\title{
SALINE SONOSALPINGOGRAPHY IN FEMALE INFERTILITY
}

\author{
Shravya Madhu¹, Shifana Shahana Kaisery², Lekhashree ${ }^{3}$, Nidhi Sharma ${ }^{4}$
}

${ }_{1}^{1}$ MBBS Student, Saveetha Medical College, Saveetha University, Chennai, Tamilnadu, India. 2MBBS Student, Saveetha Medical College, Saveetha University, Chennai, Tamilnadu, India.

3MS Student, Department of Obstetrics and Gynaecology, Saveetha Medical College, Saveetha University, Chennai, India.

4 Professor, Department of Obstetrics and Gynaecology, Saveetha Medical College, Saveetha University, Chennai, India.

\section{ABSTRACT}

\section{BACKGROUND}

There has been an increase in infertile couples seeking medical help. Fallopian tube block is the most common finding in the female partner. We wanted to determine the predictive value of sonosalpingography (SSG) and hysterosalpingography (HSG) in diagnosing tubal pathology in female partners of infertile couples.

\section{METHODS}

This quasi-experimental study included 30 patients who were studied by SSG and 30 patients who were studied by HSG. All 60 patients underwent diagnostic laparoscopic chromopertubation to confirm the findings.

\section{RESULTS}

HSG has better specificity than SSG in diagnosis of tubal block ( $90 \% \mathrm{v} / \mathrm{s} 56 \%$ ).

\section{CONCLUSIONS}

SSG is safe, painless, sensitive modality of prediction of tubal pathology. It has low specificity and negative spill should be reconfirmed by HSG or laparoscopic chromopertubation.

HOW TO CITE THIS ARTICLE: Madhu S, Kaisery SS, Lekhashree, et al. Saline sonosalpingography in female infertility. J. Evolution Med. Dent. Sci. 2019;8(16):1280-1282, DOI: 10.14260/jemds/2019/285

\begin{abstract}
BACKGROUND
Human fertilization takes place in the ampulla of the fallopian tube. Fallopian tubes originate from the uterine cornua, is few $\mathrm{mm}$ wide and 10-12 $\mathrm{cms}$ long coiled structures and are located between the uterus and ovaries. Fallopian tubal factors are the commonest cause of female infertility.(1) Tubal factors can be anatomical structural defects or functional defects. Structural defects are tubal blocks caused by chronic pelvic inflammatory diseases, hydrosalpinx, peritubal adhesions, and tubal endometriosis. Functional defects include the abnormal tubal peristalsis, fimbrial ovum pick up defects and defects in the fallopian tubal fluids. Anatomical defects of tube can be identified by grey scale sonography and saline/contrast sonosalpingography.
\end{abstract}

\section{Aim of The Study}

To determine the predictive value of sonosalpingography (SSG) and hysterosalpingography (HSG) in diagnosing tubal pathology in female partners of infertile couples.

\section{METHODS}

This quasi-experimental study was conducted in Department of Obstetrics and Gynaecology in Saveetha Medical College and Hospital from January 2017-December 2018.

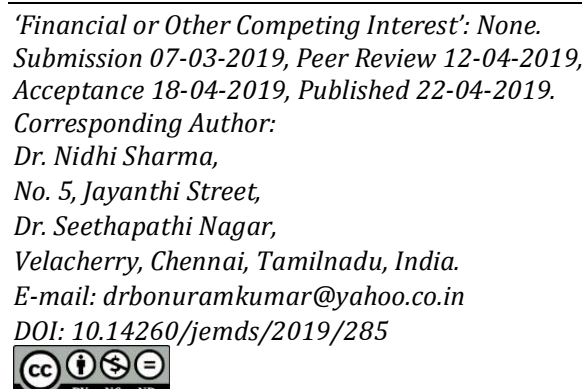

This study was approved by the ethical and research board. Written consent was obtained in all cases in the local language. Inclusion criteria were infertility for 2 years duration and regular menstrual cycles. Thirty patients who gave written informed consent were recruited by consecutive enumerative sampling for sonosalpingography study. Thirty patients underwent hysterosalpingography for evaluation of tubal patency.

All examinations were performed using transvaginal probe (Voluson E8, GE Medical Systems, and Mindray) to assess the uterus, ovaries, vesicouterine pouch, and pouch of Douglas (POD). The patient is asked to empty the bladder and baseline endovaginal scan is performed. First the approximate location of the tube is visualized by identifying the ovary and endometrium indenting at the tubal ostium. The procedure is performed with a sonosalpingography cannula (SION cannula).

The normal saline is introduced through into the endometrial cavity and is followed for spillage around the ovary since the fimbriated end of tube is near the ovary. When there is no definite spillage a contrast is introduced to delineate the tubes. Sometimes normal saline is introduced again to maximize the delineation of tubes. True obstruction is identified by lack of egress of saline contrast from the fimbriated end of tube even after 15-20 minutes. The normal tubal lumen is identified as thin serpiginous structure of a diameter of $1 \mathrm{~mm}$ in the plane axial between the uterine isthmus and ovary. Sometimes tubal endosalpingeal folds can be recognized. Surrounding anechoic fluid can identify adhesions between the ovary and bowel. Sliding sign is also useful for diagnosing peritubal adhesions. Ovarian adhesions were diagnosed in three patients with SSG spill negative when the ovaries could not be mobilized at all by gentle pressure with the vaginal probe and abdominal pressure using the examiner's free hand.(2) Salpingitis isthmic nodosa 
was missed by SSG but it was identified as the peritubal pathology during laparoscopy.

Hysterosalpingography was done in another 30 patients and results were compared after laparoscopic chromopertubation.

\section{Statistical Analysis}

Descriptive statistics was used to find significant levels of differences. Fischer exact test and chi square test were used to analyse the significant variables. The sensitivity, specificity, positive predictive value, negative predictive value, and likelihood ratio positive and likelihood ratio negative for a cut-off mean in the prediction of tubal block were calculated. Differences were considered significant when $\mathrm{p}<0.05$. Logistic regression was used to obtain the Odd's ratio (OR) and accuracy at 95\% confidence interval (CI). Statistical analysis was done using MedCalc (Belgium).

\section{RESULTS}

Table 1 summarizes the sonosalpingography tubal spillage as compared with laparoscopic chromopertubation. In SSG $17 / 30$ patients were spill positive suggesting open tubes while $13 / 30$ patients were spill negative suggesting mechanically blocked fallopian tubes. Though the site of block could not be detected in SSG. Mechanical tubal block was further investigated, and the causes were endometriosis, chronic PID, hydrosalpinx and tuberculosis.

\begin{tabular}{|c|c|c|c|}
\hline $\begin{array}{c}\text { Peritoneal Spillage } \\
\text { after } \\
\text { Saline/Contrast }\end{array}$ & $\begin{array}{c}\text { Laparoscopic } \\
\text { Tubal Patency }\end{array}$ & $\begin{array}{c}\text { Laparoscopy } \\
\text { Tubal Block }\end{array}$ & Total \\
\hline SSG Spill positive & 16 & 1 & $\mathbf{1 7}$ \\
\hline SSG Spill negative & 12 & 1 & $\mathbf{1 3}$ \\
\hline Total & $\mathbf{2 8}$ & $\mathbf{2}$ & $\mathbf{3 0}$ \\
\hline
\end{tabular}

Table 1. Tubal Patency Test by Sonosalpingography Tubal Spillage and Laparoscopic Chromopertubation

Table 2 depicts the comparison of hysterosalpingography tubal spillage with laparoscopic chromopertubation. In HSG $12 / 30$ patients were spill positive suggesting open tubes while $18 / 30$ patients were spill negative suggesting mechanically blocked fallopian tubes. The site of block was detected in HSG. Mechanical tubal block was further investigated, and the causes were fimbrial block, chronic PID, hydrosalpinx and tuberculosis.

\begin{tabular}{|c|c|c|c|}
\hline $\begin{array}{c}\text { Peritoneal } \\
\text { Spillage } \\
\text { after Contrast }\end{array}$ & $\begin{array}{l}\text { Laparoscopic } \\
\text { Tubal Patency }\end{array}$ & $\begin{array}{c}\text { Laparoscopy } \\
\text { Tubal Block }\end{array}$ & Total \\
\hline HSG Spill Positive & 11 & 1 & 12 \\
\hline HSG Spill Negative & 8 & 10 & 18 \\
\hline Total & 19 & 11 & 30 \\
\hline \multicolumn{4}{|c|}{$\begin{array}{l}\text { Table 2. Tubal Patency Test by Hysterosalpingography } \\
\text { Tubal Spillage and Laparoscopic Chromopertubation }\end{array}$} \\
\hline
\end{tabular}

Table 3 is a compilation. This table shows that HSG has better accuracy in diagnosing tubal patency. HSG and SSG have similar sensitivity though HSG has much higher specificity and it can also diagnose the exact site of block. Associated lesions like endometriosis can be missed in HSG.

\begin{tabular}{|c|c|c|c|c|c|c|c|}
\hline $\begin{array}{c}\text { Tube } \\
\text { Patency } \\
\text { Test }\end{array}$ & Sensitivity & Specificity & $\begin{array}{l}\text { PPV } \\
\text { (\%) }\end{array}$ & $\begin{array}{l}\text { NPV } \\
(\%)\end{array}$ & LR+ & LR- & Accuracy \\
\hline & & & & & & & \\
\hline 11 & & & & . & 6.37 & 0.46 & 10.0070 \\
\hline \multicolumn{8}{|c|}{$\begin{array}{c}\text { Table 3. Diagnostic Accuracy of Sonosalpingography (SSG) } \\
\text { and Hysterosalpingography (HSG) }\end{array}$} \\
\hline
\end{tabular}

\section{DISCUSSION}

Normal tubes cannot be visualized in grey scale ultrasonography, as they are isoechoic.(3) Saline and fluid contrast can be introduced through the uterine end and fluid movement can be traced by Doppler shift using colour Doppler mode. Adhesions, cysts or fluid seen around the tubes raises the suspicion of tubal pathology.(4) Sonosalpingography is not a substitute for hysterosalpingography or Laparoscopy but it is cost effective, non-invasive screening procedure in patients of infertility. This finding is also supported by a few studies done earlier. $(5,6,7)$ The recent FOAM study also suggests that SSG is a useful prediction tool.(8)

Sonosalpingography cannot diagnose the salpingitis isthmic nodosa. This condition is better identified on Hysterosalpingography. Tubal obstruction should be differentiated from tubal spasm and administration of antispasmodics like IM hyoscine bromide is done routinely to minimize pain and spasm during the procedure.(9) Additional information is obtained if Colour Doppler is added and gate placed at the isthmic end and a Doppler shift confirms the patency. Some centers use a 20-60 ml solution of Hyalase, Ciplox and dexamethasone to flush the tubes via Sion cannula and spill is studied from the fimbrial end. Hydrosalpinx appears as fusiform cystic structure near the ovary. Relative motion of the hydrosalpinx and ovary should be observed by sliding sign. Additional benefit is that uterus and tubal outline and congenital malformations can be seen.

\section{CONCLUSIONS}

The diagnostic accuracy, sensitivity and specificity of sonosalpingography are comparable to hysterosalpingography as assessed by laparoscopic chromopertubation. The functional aspects of tube-like peristalsis and mobility are also assessed. Tubal peristalsis is usually not seen in hysterosalpingography. Additionally, SSG can help to visualize myoma, adhesions, and polyps in the endometrial cavity and there is no radiation exposure. Laparoscopy is the gold standard and also complementary to HSG and SSG as it also helps in identifying peritubal adhesions and tubal endosalpingiosis outside the tubes. Laparoscopy has an additional advantage, as adhesiolysis and tubal endometriosis resection can be done at the same time.

\section{REFERENCES}

[1] Stern J, Peters AJ, Coulam CB. Color Doppler ultrasonography assessment of tubal patency: a comparison study with traditional techniques. Fertil Steril 1992;58(5):897-900.

[2] Larciprete G, Valli E, Meloni P, et al. Ultrasound detection of the "sliding viscera" sign promotes safer laparoscopy. J Minim Invasive Gynecol 2009;16(4):445-9. 
[3] Menakaya U, Reid S, Infante F, Condous G. The 'sliding sign' in conjunction with sonovaginography: is this the optimal approach for the diagnosis of Pouch of Douglas obliteration and posterior compartment deep infiltrating endometriosis? Australas J Ultrasound Med 2013;16(3):118-23.

[4] Luciano DE, Exacoustos C, Luciano AA. Contrast ultrasonography for tubal patency. J Minim Invasive Gynecol 2014;21(6):994-8.

[5] Luciano DE, Exacoustos C, Johns DA, et al. Can hysterosalpingo-contrast sonography replace hysterosalpingography in confirming tubal blockage after hysteroscopic sterilization and in the evaluation of the uterus and tubes in infertile patients? Am J Obstet Gynecol 2011;204(1):79.e1-5.

[6] Exacoustos C, Zupi E, Carusotti C, et al. Hysterosalpingo-contrast sonography compared with hysterosalpingography and laparoscopic dye pertubation to evaluate tubal patency. J Am Assoc Gynecol Laparosc 2003;10(3):367-72.
[7] Dijkman AB, Mol BW, van der Veen F, et al. Can hysterosalpingocontrast-sonography replace hysterosalpingography in the assessment of tubal subfertility? Eur J Radiol 2000;35(1):44-8.

[8] Van Rijswijk J, Van Welie N, Dreyer K, et al. The FOAM study: is Hysterosalpingo foam sonography (HyFoSy) a cost-effective alternative for hysterosalpingography (HSG) in assessing tubal patency in subfertile women? Study protocol for a randomized controlled trial. BMC women's health 2018;18(1):64.

[9] Socolov D, Boian I, Boiculese L, et al. Comparison of the pain experienced by infertile women undergoing hysterosalpingo contrast sonography or radiographic hysterosalpingography. Int J Gynaecol Obstet 2010;111(3):256-9. 